\title{
Parts and Wholes in Pictorial Art
}

\author{
Jan Koenderink ${ }^{1,2}$ \\ ${ }^{1}$ Laboratory of Experimental Psychology, Katholieke Universiteit Leuven, \\ Tiensestraat 102, 3000 Leuven, Belgium \\ ${ }^{2}$ Psychologische Functieleer, Faculteit Sociale Wetenschappen, Utrecht University, \\ Martinus J. Langeveldgebouw, Heidelberglaan 1, 3584 CS Utrecht, The Netherlands
}

\section{Supplementary Notes}

Note S1. Maurice Denis (1890) famously wrote: 'It is well to remember that a picture before being a battle horse, a nude woman, or some anecdote, is essentially a flat surface covered with colours assembled in a certain order'.

Note S2. I use 'double-sided' so as to avoid confusion with Husserl's notion of 'double intentionality'. I do not use 'shared intentionality' because artist and observer do not necessarily know each other, indeed, might live centuries or continents apart. There is no collaborative aspect in the case of art appreciation.

Note S3. This is evidently not generic looking. It is a special mode of using the eyes that seems to be limited to Homo sapiens. I limit myself to this mode in this paper, no excuses.

Note S4. Paulus Potter (Enkhuizen 1625 - Amsterdam 1654) was a Dutch painter who specialized in animals in landscapes.

Note S5. Mark Tansey (born San Jose 1949) is an American painter.

Note S6. Notice that this involves additional layers of intentionality.

Note S7. From the Greek 'part': $\mu \varepsilon \rho о \zeta$.

Note S8. Franz Clemens Honoratus Hermann Brentano (1838-1917).

Note S9. Sir Peter Paul Rubens (1577-1640), was a Flemish Baroque painter and a proponent of an extravagant Baroque style. 
Note S10. A Sunday Afternoon on the Island of La Grande Jatte - 1884 (Un dimanche après-midi à l'île de la Grande Jatte) is one of Georges Seurat's (1859-1891) most famous works, and is an example of pointillism.

Note S11. The Mona Lisa (La Gioconda or La Joconde, or Portrait of Lisa Gherardini (wife of Francesco del Giocondo)) is a half-length portrait of a woman by the Italian artist Leonardo da Vinci (1452-1519).

Note S12. El Greco, born Doménikos Theotokópoulos, (1541-1614) was a painter, sculptor and architect of the Spanish Renaissance.

Note S13. The Ghent Altarpiece or Adoration of the Mystic Lamb (Het Lam Gods, completed 1432) is a huge, complex Early Flemish polyptych panel painting. It was begun by Hubert van Eyck, who died in 1426 while work was underway, and it was completed by his younger brother Jan van Eyck (born before ca. 1395 - died before ca. 9 July 1441).

Note S14. Pablo Diego José Francisco de Paula Juan Nepomuceno María de los Remedios Cipriano de la Santísima Trinidad Ruiz y Picasso, known as Pablo Picasso (1881-1973), was a Spanish painter, sculptor, printmaker, ceramicist, and stage designer who spent most of his adult life in France.

Note S15. Salvador Domingo Felipe Jacinto Dalí i Domènech, 1st Marqués de Dal de Pubol (1904-1989), known as Salvador Dalí, was a prominent Spanish surrealist painter.

Note S16. Kazimir Severinovich Malevich (1879-1935) was a Russian painter and art theoretician.

Note S17. Paul Jackson Pollock (1912-1956), known as Jackson Pollock (or informally as 'Jack the Dripper'), was an influential American painter and a major figure in the abstract expressionist movement.

Note S18. Félix Edouard Vallotton (1865-1925) was a Swiss painter and printmaker associated with Les Nabis.

Note S19. Vincent Willem van Gogh (1853-1890) was a Dutch post-Impressionist painter.

Note S20. Aristide Maillol (1861-1944) was a French Catalan sculptor, painter, and printmaker.

Note S21. Giovanni Battista di Jacopo (1494-1540), known as Rosso Fiorentino, or Il Rosso, was an Italian Mannerist painter in the Florentine school.

Note S22. Thus, with P standing for the parthood relation one would write

- Reflexivity P $x x$ 
- Transitivity $(\mathrm{P} x y \wedge \mathrm{P} y z) \rightarrow \mathrm{P} x z$

- Antisymmetry $(\mathrm{P} x y \wedge \mathrm{P} y x) \rightarrow x=y$

and so forth. Such formulae decorate countless philosophical papers to best advantage.

Note S23. Michelangelo di Lodovico Buonarroti Simoni (1475-1564), commonly known as Michelangelo, was an Italian Renaissance sculptor, painter, architect, poet, and engineer.

Note S24. The David is a Renaissance sculpture created between 1501 and 1504, by Michelangelo. The giant marble statue (nicknamed Il biancone by the natives) of a standing male nude is $5.17 \mathrm{~m}$ high.

Note S25. Johannes Misset (1862-1922), Dutch painter; Jean-Étienne Liotard (1702-1789) was a Swiss-French painter, art connoisseur and dealer.

Note S26. Droste is a cocoa and chocolate factory based at Haarlem, The Netherlands, which started as a bakery in 1863. It became well known worldwide during the 1920s and 1930 and it still exists.

Note S27. I use 'line' in the sense of 'curve' or 'trace', not implying rectilinearity.

Note S28. Joseph Jastrow (1863-1944) was an American psychologist. Jastrow's cartoon was based on one originally published in Harper's Weekly (Nov. 19, 1892, p. 1114) which, in turn, was based on an earlier illustration in Fliegende Blätter, a German humour magazine (Oct. 23, 1892, p. 147). Jastrow's publication is: Jastrow, J. (1899). The Mind's Eye, Pop. Sci. Monthly 54, 299-312.

Note S29. The so called Identity of Indiscernibles.

Note S30. A 'presentation' is the content of momentary visual awareness. Presentations are timeless, so I mention instances of presentations, but will not imply any temporal order.

Note S31. I say this because it is a moot point to what extent presentations may be held to be temporally ordered. Each presence is complete, and timeless in that it contains its own past and future. One presence is fully independent of any other one.

Note S32. The Aphrodite of Milos, or the Venus de Milo, is an ancient Greek statue. It was created sometime between 130 and $100 \mathrm{BCE}$. It is believed to depict Aphrodite, the Greek goddess of love and beauty ('Venus' to the Romans). The marble sculpture is slightly larger than life size. Its arms and original plinth were lost following the discovery. 
Note S33. The Belvedere Torso is a fragment of a nude male statue. It is signed by an Athenian sculptor 'Apollonios son of Nestor'. The statue is documented in the collection of Cardinal Prospero Colonna in Monte Cavallo, Rome from the 1430s.

Note S34. Giambologna (1529-1608) was born as Jean Boulogne. He is incorrectly known as Giovanni da Bologna. Giambologna was a sculptor, known for his marble and bronze statuary in a late Renaissance or Mannerist style. Aristide Joseph Bonaventure Maillol (1861-1944) was a French Catalan sculptor, painter and printmaker.

Note S35. This is occasionally referred to as 'tarachopia', meaning 'scrambled vision'.

Note S36. Saul Steinberg (1914-1999) was a Romanian-born American cartoonist and illustrator, best known for his work for The New Yorker.

Note S37. Clarence Coles Phillips (1880-1927) was an American artist and illustrator. He is known for his stylish images of women, especially his 'vanishing girls', created for advertisements and covers of popular magazines.

Note S38. Chico Hayasaki is a Tokyo based, active illustrator. Peter Jeroense is an active Dutch illustrator.

Note S39. Edgar Degas (1834-1917) was a French artist famous for his work in painting, sculpture, printmaking and drawing.

Note S40. René François Ghislain Magritte (1898-1967) was a Belgian surrealist artist.

Note S41. 'Hyperextensionality' in Goodman's (1958) sense means: things built up from exactly the same atoms are identical.

Note S42. Roy Lichtenstein (1923-1997) was a prominent American pop artist.

Note S43. Vera Gräfin von Lehndorff-Steinort or Veruschka von Lehndorff (born 1939) is a German model, actress, and artist who was popular during the 1960s. She is known professionally as Veruschka. Many will remember her from her part in Michelangelo Antonioni's movie Blow up.

Note S44. Pieter Cornelis ('Piet') Mondriaan, after 1906 Mondrian (18721944), was a Dutch painter, an important contributor to the De Stijl art movement and group.

Note S45. Andy Warhol (1928-1987) was an American pop artist. 
Note S46. Hans Makart (1840-1884) was a nineteenth century Austrian academic history painter, designer, and decorator.

Note S47. Jean-Auguste-Dominique Ingres (1780-1867) was a French Neoclassical painter.

Note S48. Suzanne Unrein is a contemporary American painter.

Note S49. Genesis 2:19-20: 'And out of the ground the Lord God formed every beast of the field, and every fowl of the air; and brought them unto Adam to see what he would call them: and whatsoever Adam called every living creature, that was the name thereof. And Adam gave names to all cattle, and to the fowl of the air, and to every beast of the field;...'.

Note S50. Paul Klee (1879-1940) is considered both a German and a Swiss painter.

Note S51. Henry Bergson, L'Evolution créatrice, 1907 (many modern editions and translations available).

\section{Supplementary Figures}
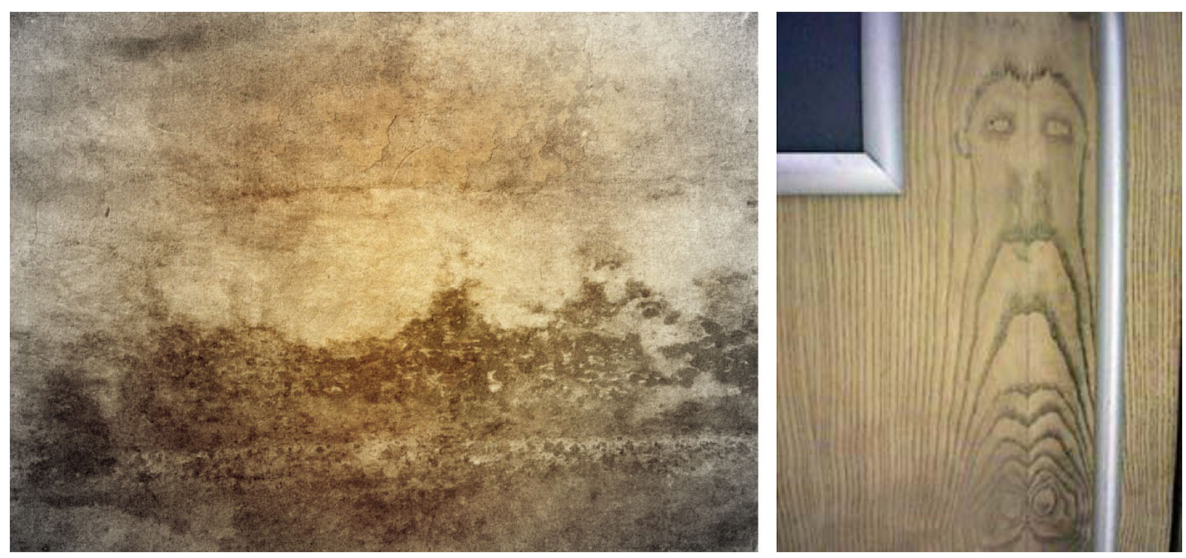

Figure S1. Left: Mold on an old wall makes for a striking picture; it might sell in an art gallery. http://e-dina.deviantart.com/art/Mold-old-wall-191943134. Right: "Jesus's face" spotted on the toilet door in Ikea Glasgow. The face of Jesus has been spotted in the most unlikely places. These portraits are evidently 'painted in the mind', although they often give rise to rumors of miraculous events. http://www.telegraph.co.uk/news/newstopics/religion/6373674/Jesussface-spotted-on-the-toilet-door-in-Ikea-Glasgow.html. 


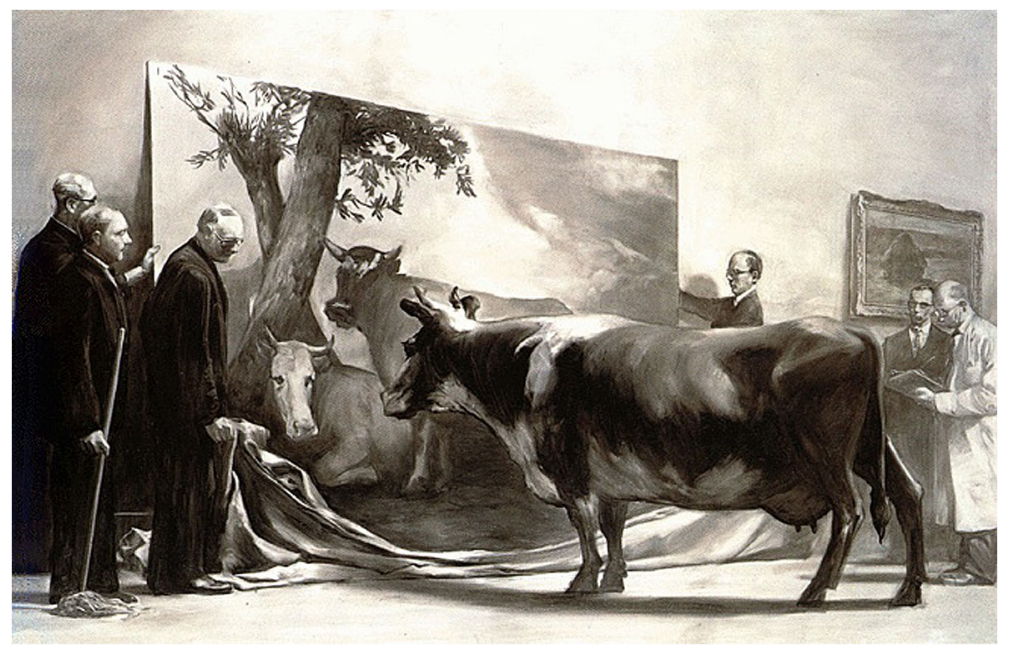

Figure S2. Mark Tansey, The Innocent Eye Test, 1981. The cow is looking at Paulus Potter's, The Young Bull, 1647. The cow remains apparently unaware of the explicit erotic overtones of this work. One concludes that in the bovine universe the painting is just another irrelevant object, despite its life size and lifelike color. (Keep in mind that this figure reproduces a painting, rather than a 'documentary photograph'.)
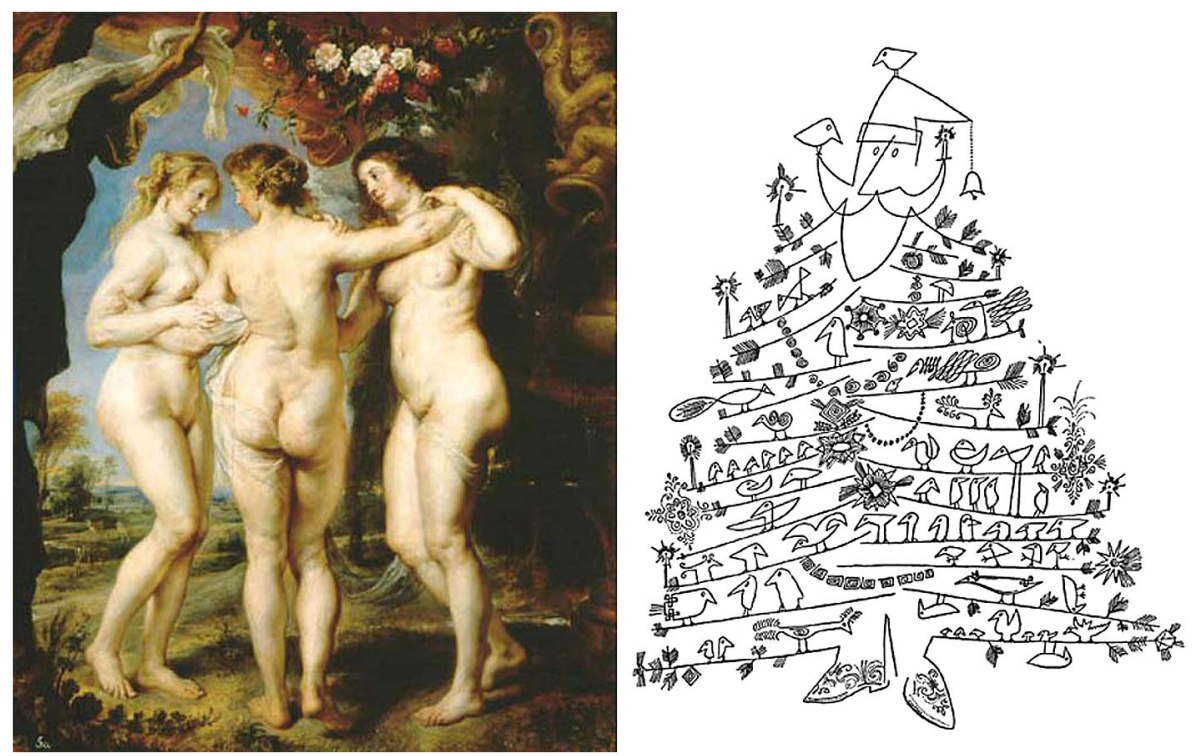

Figure S3. Left: Peter Paul Rubens, The Three Graces, 1639. Evidently three major objects, rolled into a single one. Right: Saul Steinberg: Santa Claus. Two (major) objects rolled in one? 

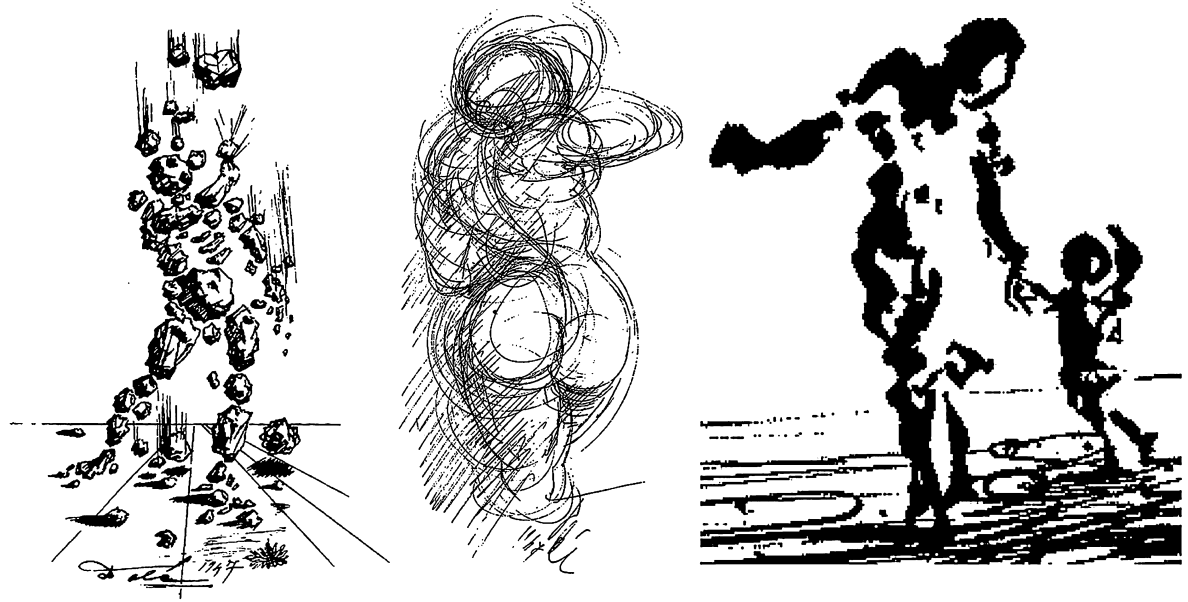

Figure S4. Three drawings by Salvador Dalí, all representing human figures. These drawings have significant structure on all ontic strata. The reader may find it rewarding to 'dissect the essential anatomy' on each level. In what sense(s) are these drawings 'different'?
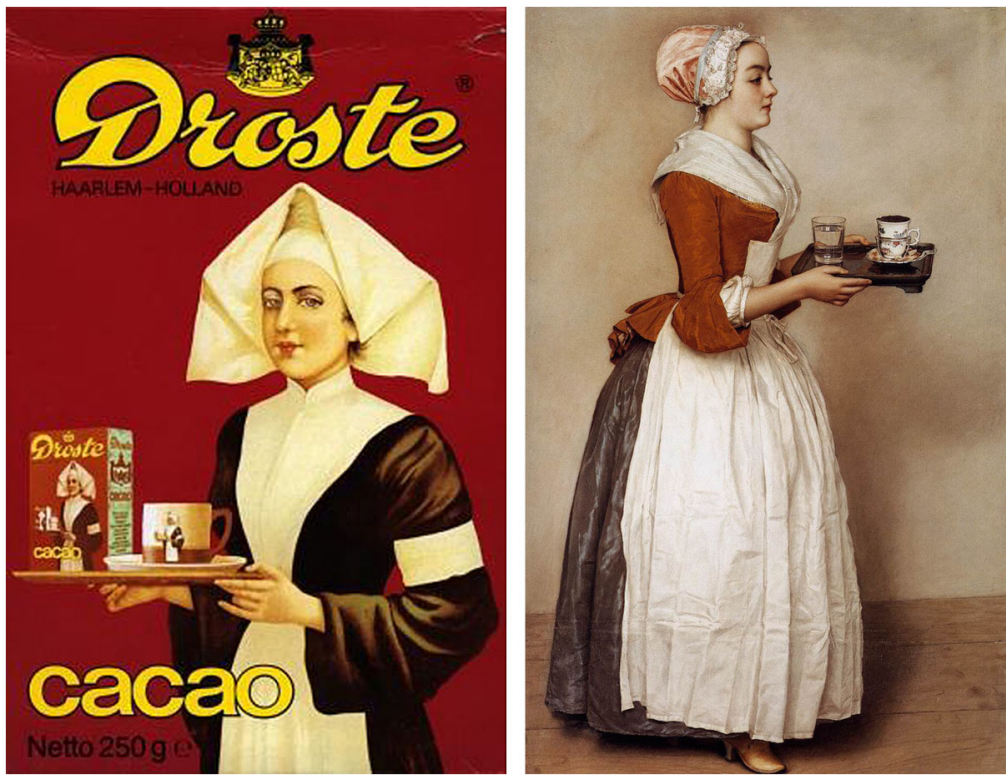

Figure S5. The nurse was drawn by Johannes Misset (after a pastel painting by Liotard, 1744/5, shown at right) around 1900. The recursive design dates from 1904. Originally the arm band carried a red cross (removed in 1914). 

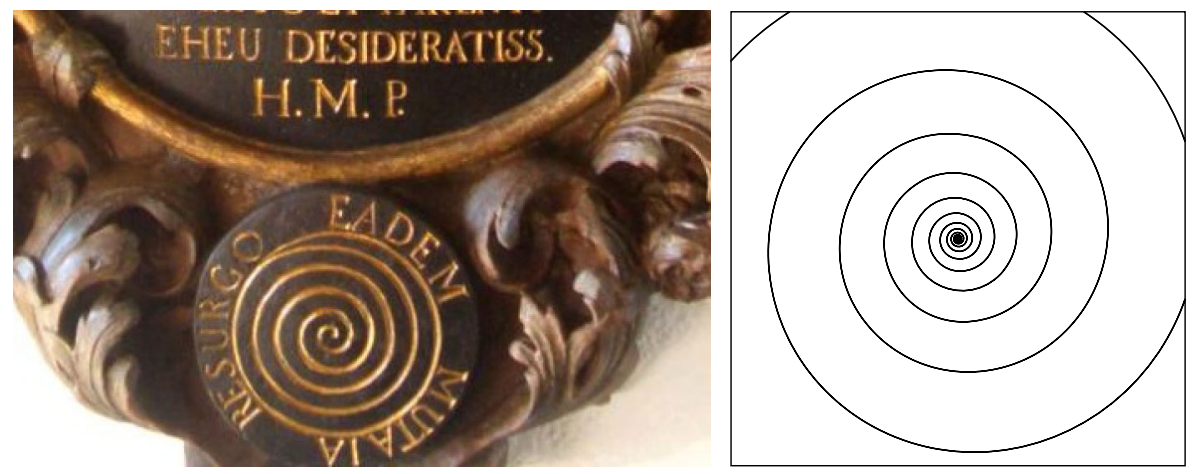

Figure S6. Left: An arc of a logarithmic spiral (unfortunately, the spiral executed by the stonemasons is an Archimedean spiral) on Jacob Bernoulli's gravestone in the Basle Münster. The motto Eadem mutata resurgo means 'Changed and yet the same, I rise again'. Right: An actual arc of the spira mirabilis. It is similar (congruent up to scale) to any part of itself.
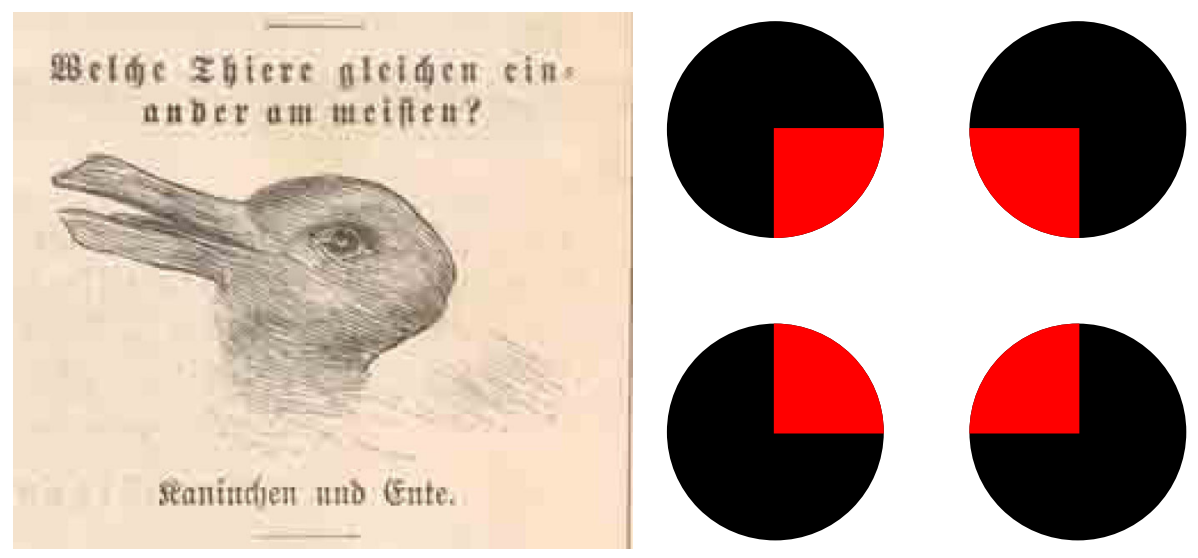

Figure S7. Left: Jastrow's infamous 'duck-rabbit'. Right: This figure evokes at least two distinct perceptions. Either the black blobs are disks with red sectors lying on the paper, or they are holes through which you see a red square. 


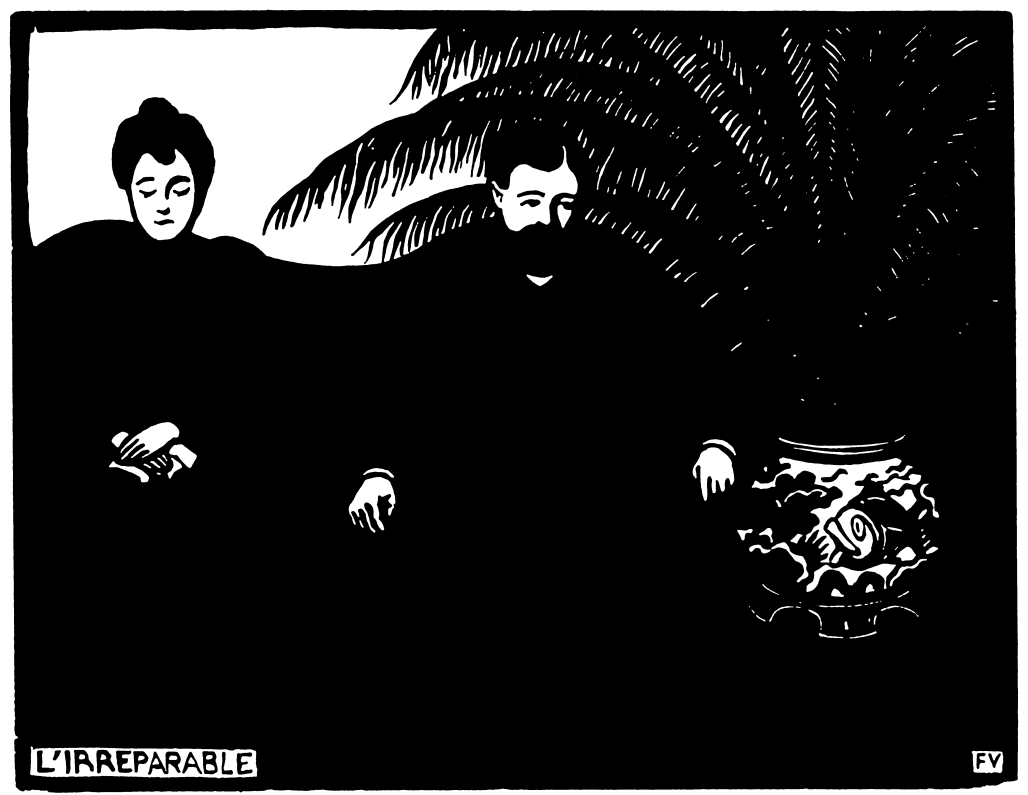

Figure S8. Felix Vallotton, L'Irreparable. Notice how the sad atmosphere pervades the overall picture.
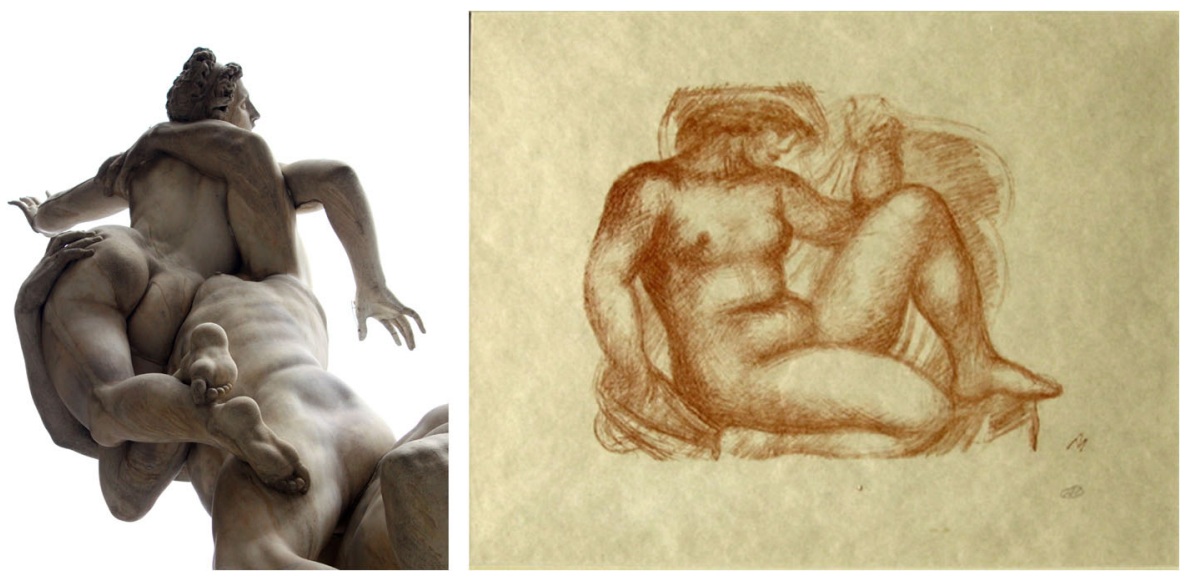

Figure S9. Detail of Giambologna's (1582) Rape of the Sabine. The fingers are an important part of the group. In Aristide Maillol's drawing Juno the hands have no further parts. 

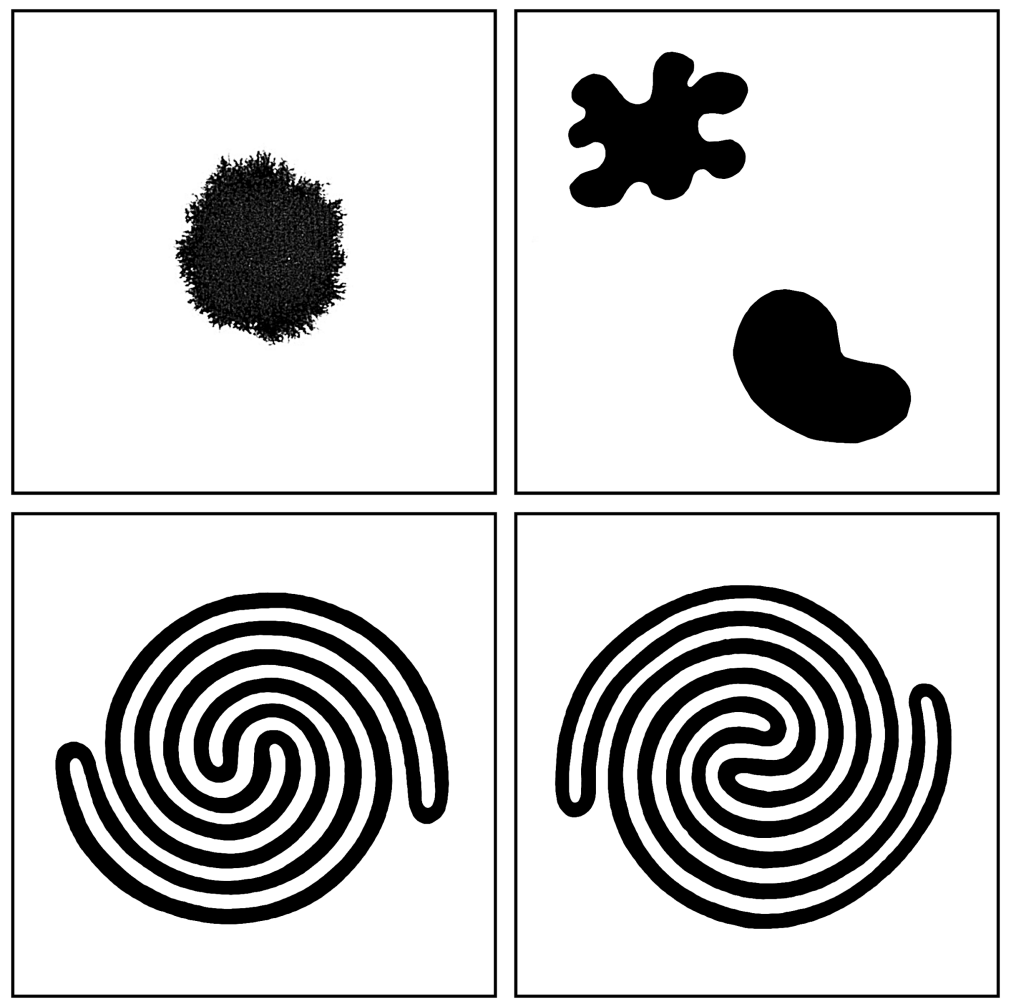

Figure S10. How many blobs are there? This is an easy task for the top row (left one, right two). But how about the bottom row? Most observers do not succeed in parsing Minsky and Papert's spirals. Has the double spiral 'two parts'? Not in visual awareness.
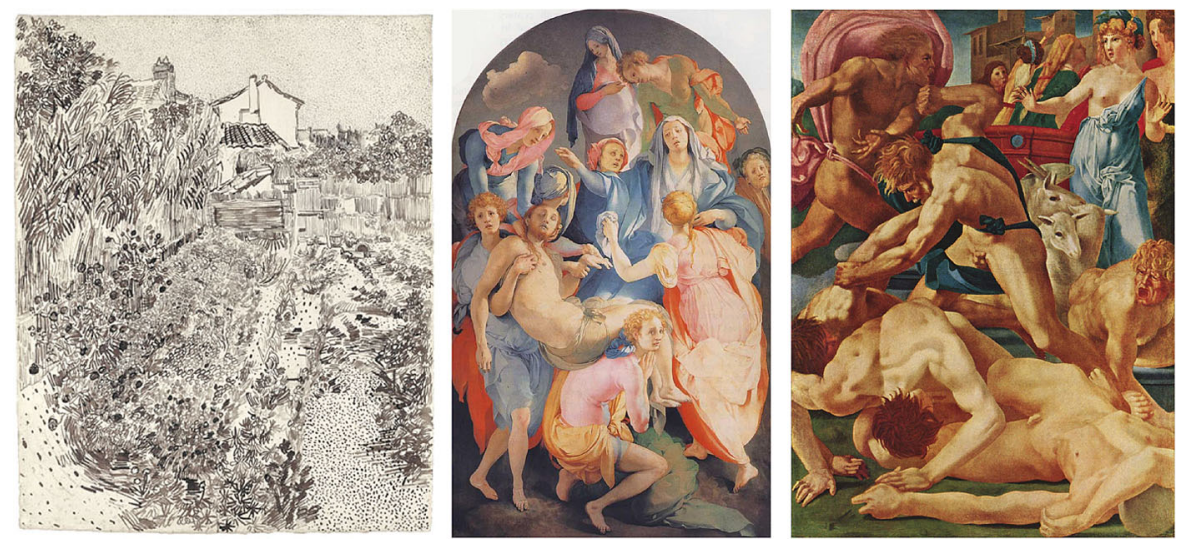

Figure S11. Left: Vincent van Gogh, Cottage garden, 1888. Notice the major vanishing point. Center: Jacopo Pontormo, Entombment, 1525-1528. Notice the center of the circular composition. Right: Rosso Fiorentino, Moses defending the daughters of Jethro, 1523. Notice pattern of lines of regard. 

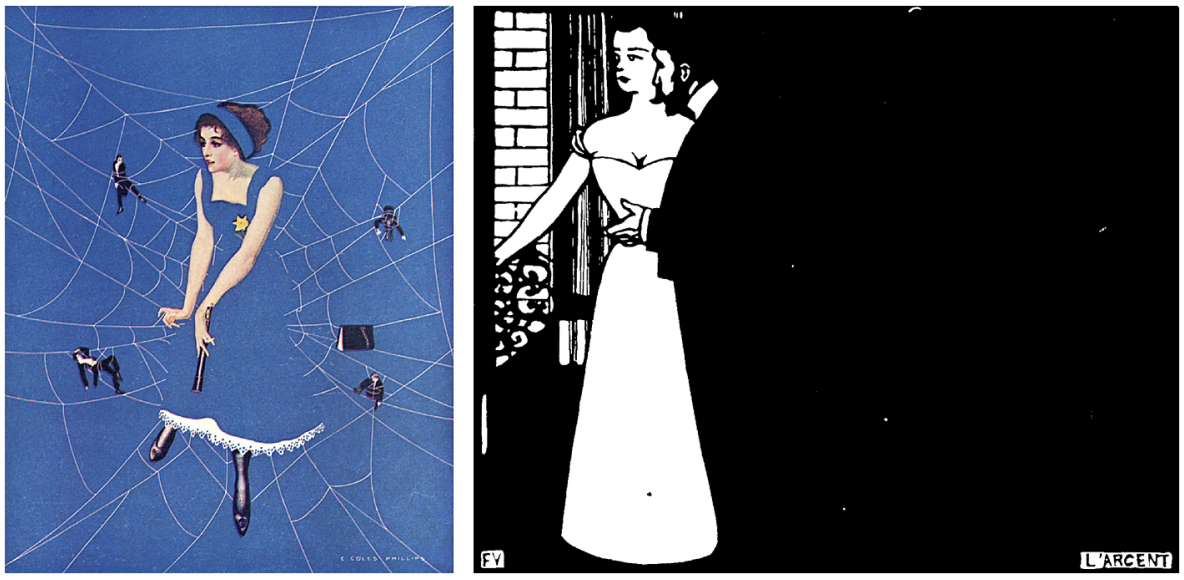

Figure S12. Left: Coles Philips. Notice the sharply delineated dress of the girl. Right: Felix Vallotton, L'Argent. Notice the right-hand edge of the man (the left-hand edge is just as interesting).
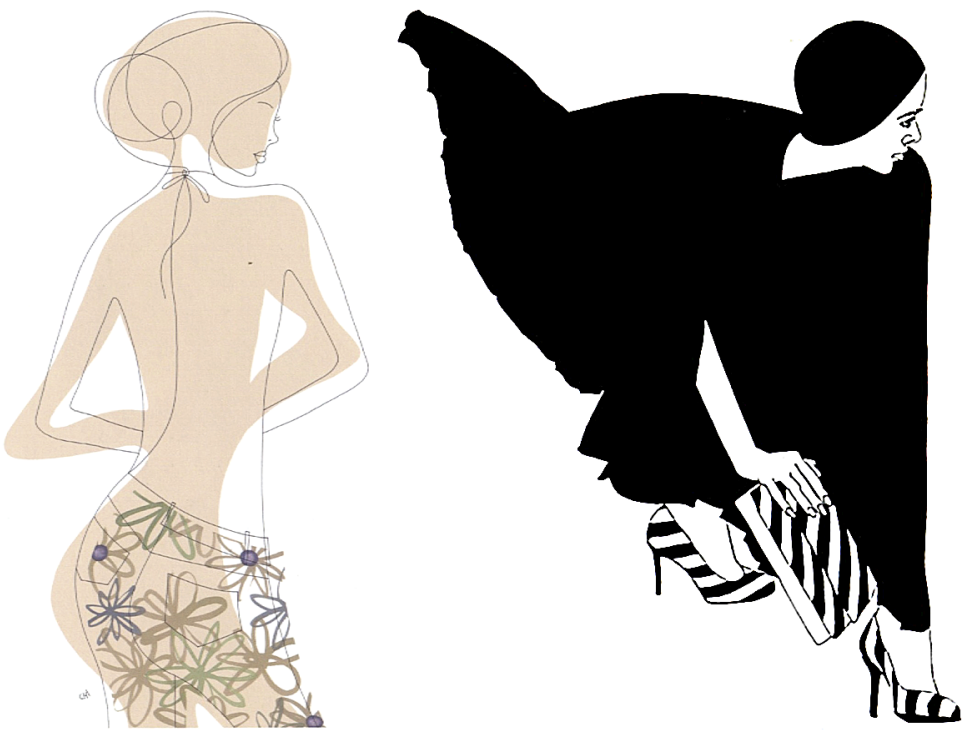

Figure S13. Left: A fashion design by Chico Hayasaki. Notice the contour. Where is the body? The ambiguity greatly increases the dynamism of the picture. Right: A fashion design by Peter Jeroense. One easily parses the big black triangle. The hidden details attribute a pleasant challenge to microgenesis. 

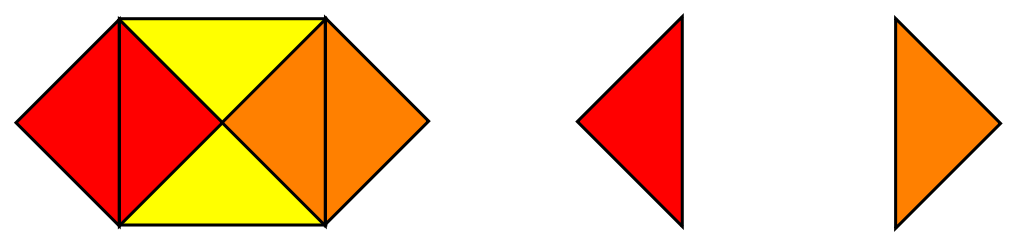

Figure S14. Left: Consider the lower yellow triangle. The center square is erected on its hypotenuse. The red and orange diamonds have been erected on its sides. Splitting the diamonds on their vertical diagonals, one notices that the figure contains six congruent triangles. Thus, the area of the center square equals the total area of the diamonds. A visual proof of the Pythagorean theorem requires 'mental parthood juggling', mostly in visual awareness, rather than reflective thought. Right: An object that is the merge of two disjunct triangles. In some contexts the object might make visual sense, for instance, you occasionally see it at the bottom of 'slide shows' running on your computer screen.

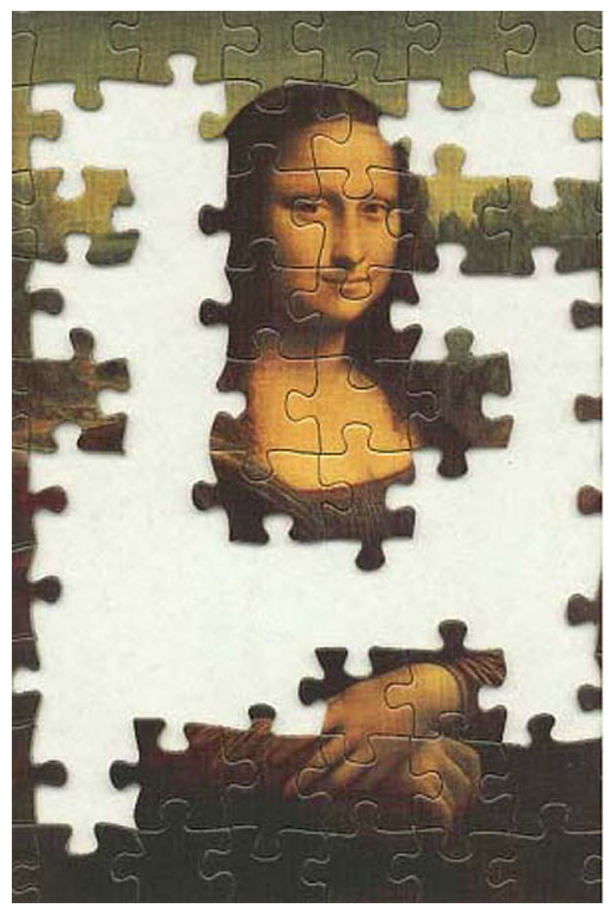

Figure S15. A Mona Lisa jigsaw puzzle ( 80 pieces). How 'natural' are these parts? What if the jigsaw puzzle (not the Mona Lisa) is the artwork? Then the pieces are 'natural', at least to the artist. 

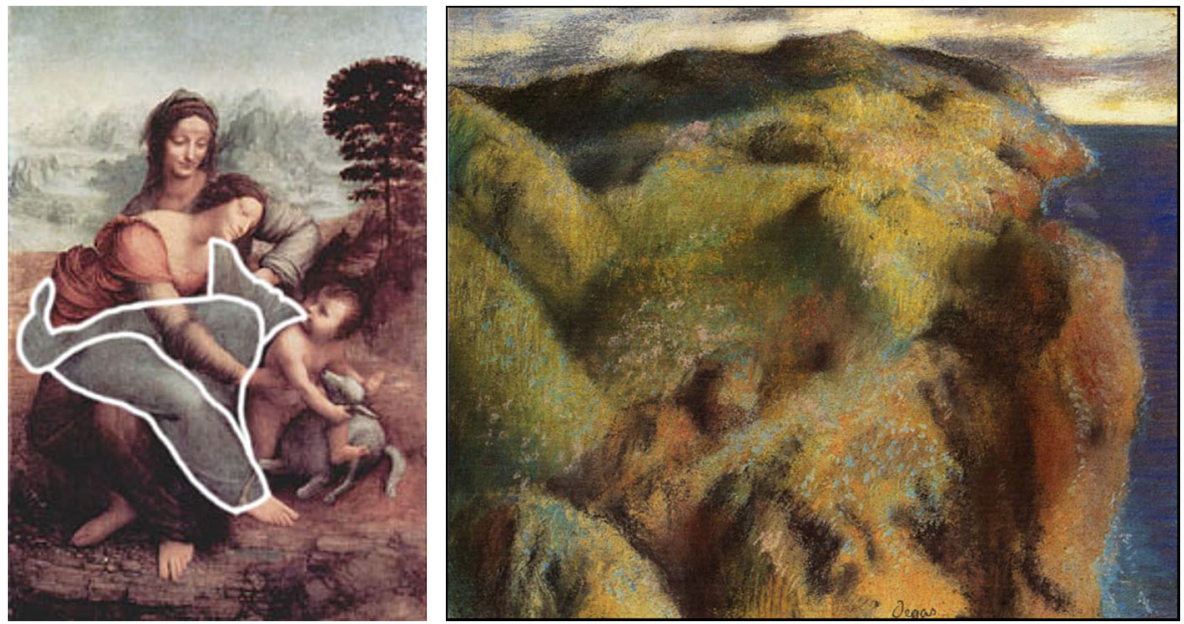

Figure S16. Left: Analysis of Sigmund Freud of a painting by Leonardo da Vinci (The Virgin and Child with St. Anne, 1508). Notice the 'vulture', is it a 'natural part'? Right: Edgar Degas, Landscape, 1892. Notice the supine female figure, buried in the hills.
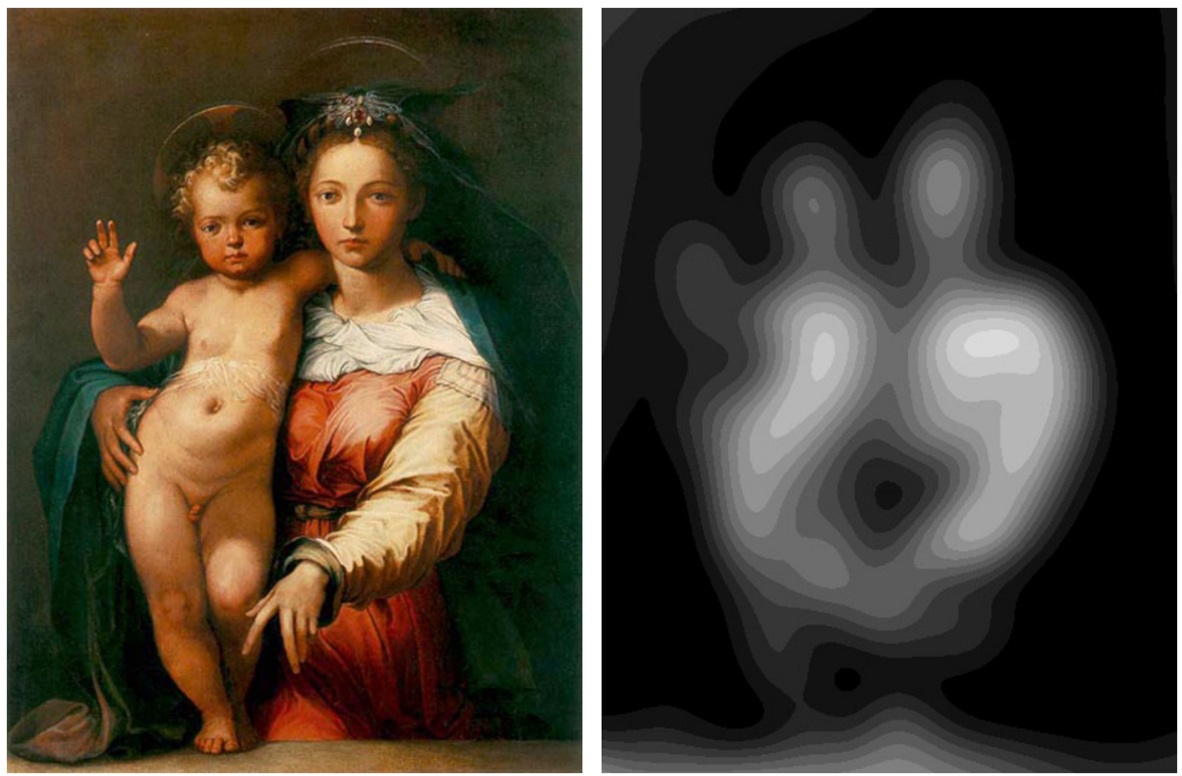

Figure S17. Piero di Giovanni Bonaccorsi (Perino del Vaga; 1501-1547), Madonna col Bambino, ca. 1535. The virgin and child visually merge into a single, unified object. The 'eye measure' merge is much cleaner (a warm colored almond shape) than the straightforward Photoshop merge (almost an anatomical cardiac shape) shown at right. 


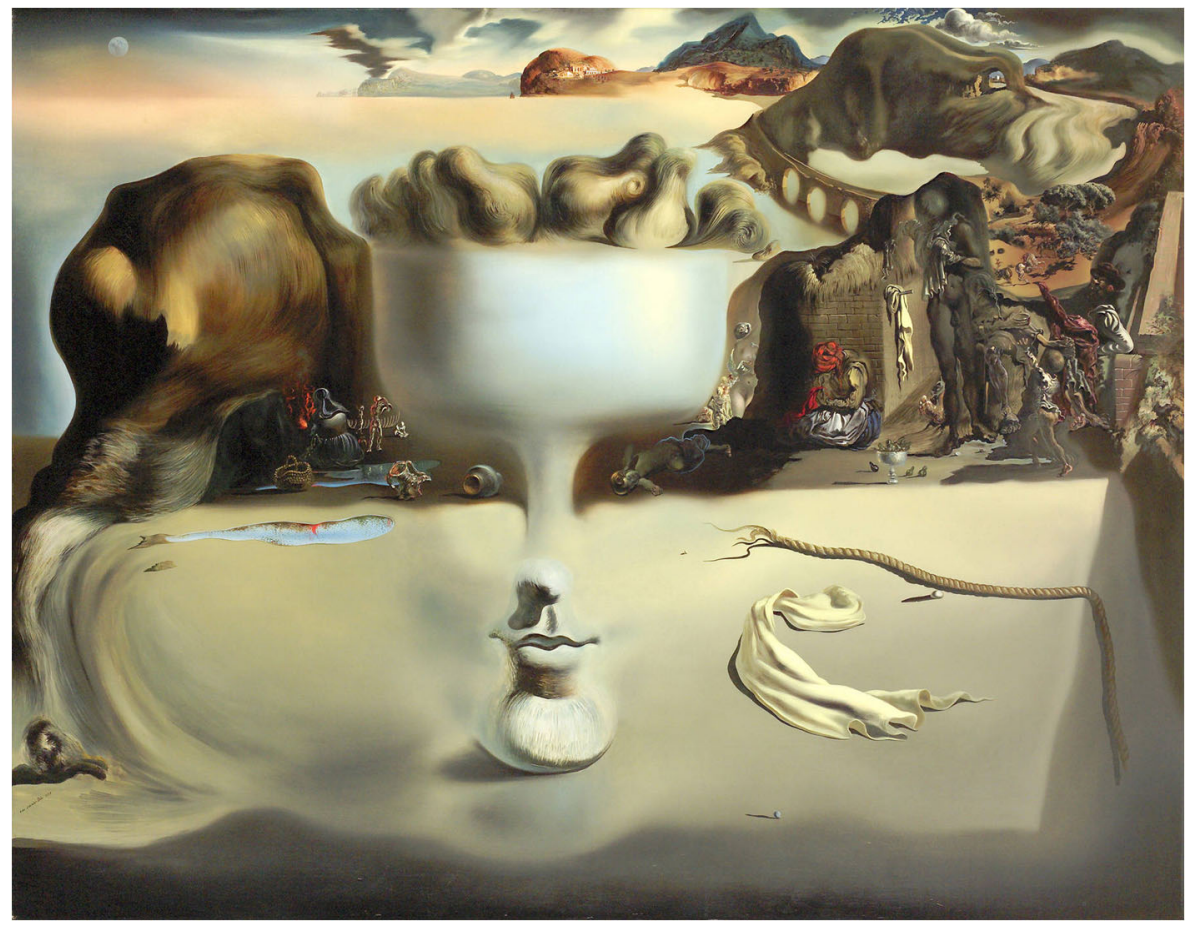

Figure S18. Salvador Dalí's Apparition of face and fruit dish on a beach (1938). Numerous odd, and sometimes surprising merges appear to 'make (visual) sense'. After cognition kicks in they further merge into nameable things.
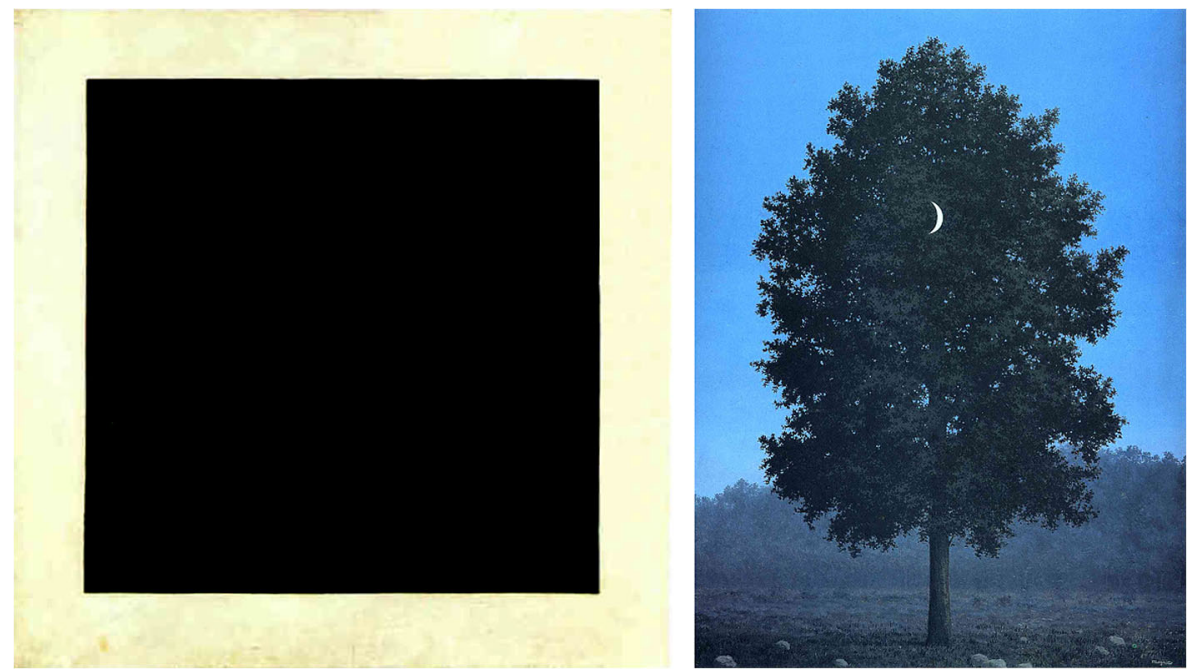

Figure S19. Left: Kasimir Malevich, Black Square, 1915. A single part? Right: René Magritte, Le Seize Septembre, 1956. How many parts has the blue sky? 


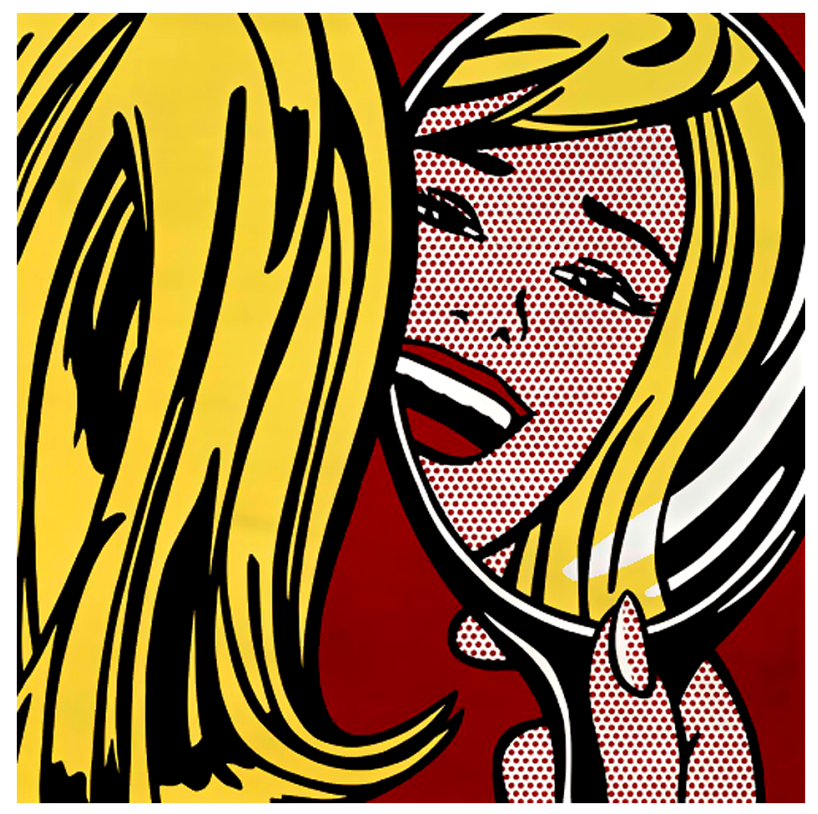

Figure S20. Roy Lichtenstein, Girl in mirror, 1964. The areas painted with fake Ben-Day dots evidently lend themselves to an atomistic mereological treatment. However, notice that Liechtenstein also paints flat areas. 


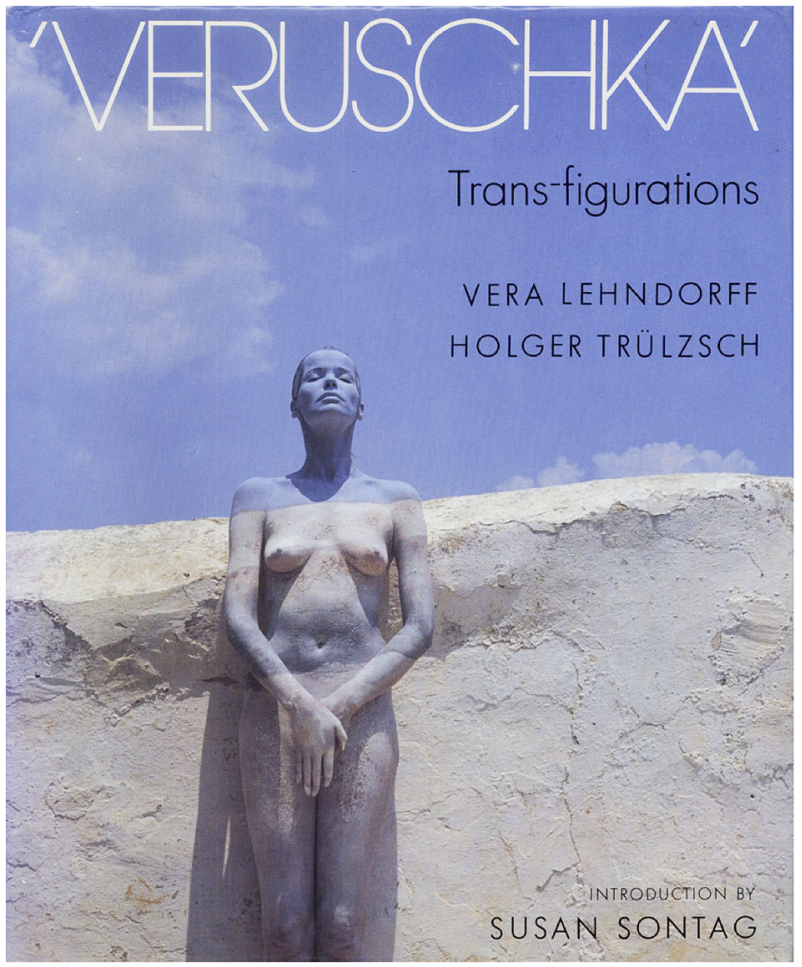

Figure S21. 'Veruschka' is Gräfin Vera von Lehndorff-Steinort (1939-present). Notice how the split sky-earth splits her body in an unnatural manner.
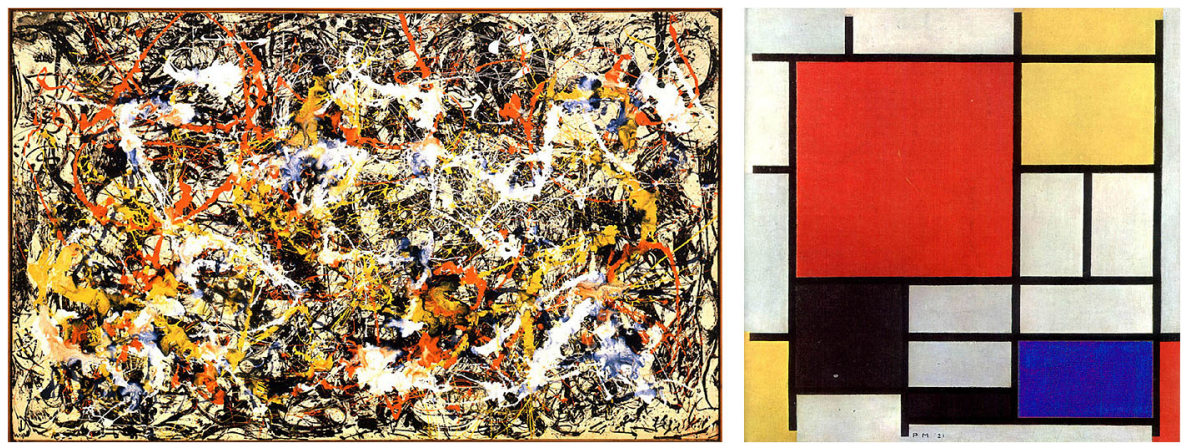

Figure S22. Left: Jackson Pollock, Convergence, 1952. Right: Piet Mondrian, Composition with Red, Yellow, Blue and Black, 1921. 

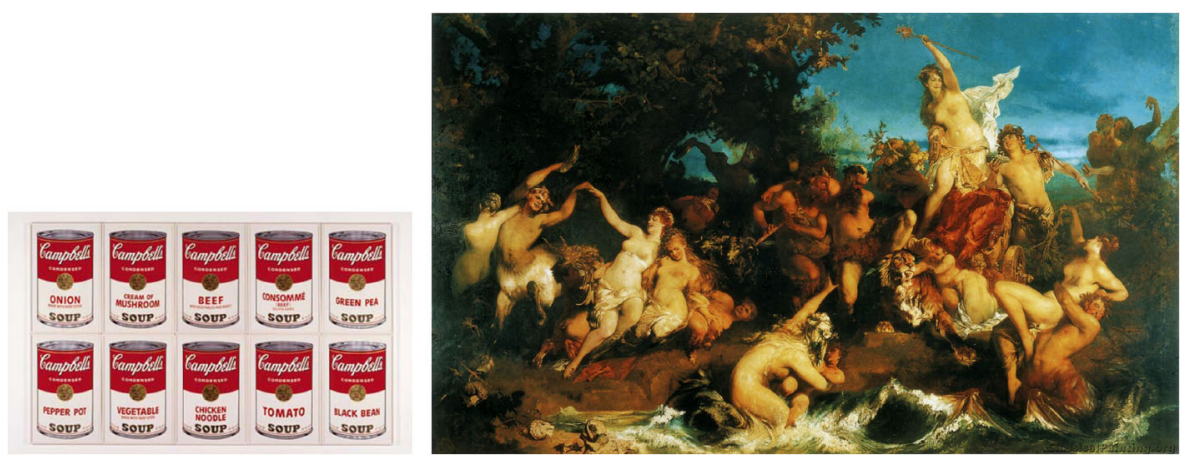

Figure S23. Left: Andy Warhol, Campbell's Soup II (1969). Right: Hans Makart, Triumph of Ariadne, 1874.
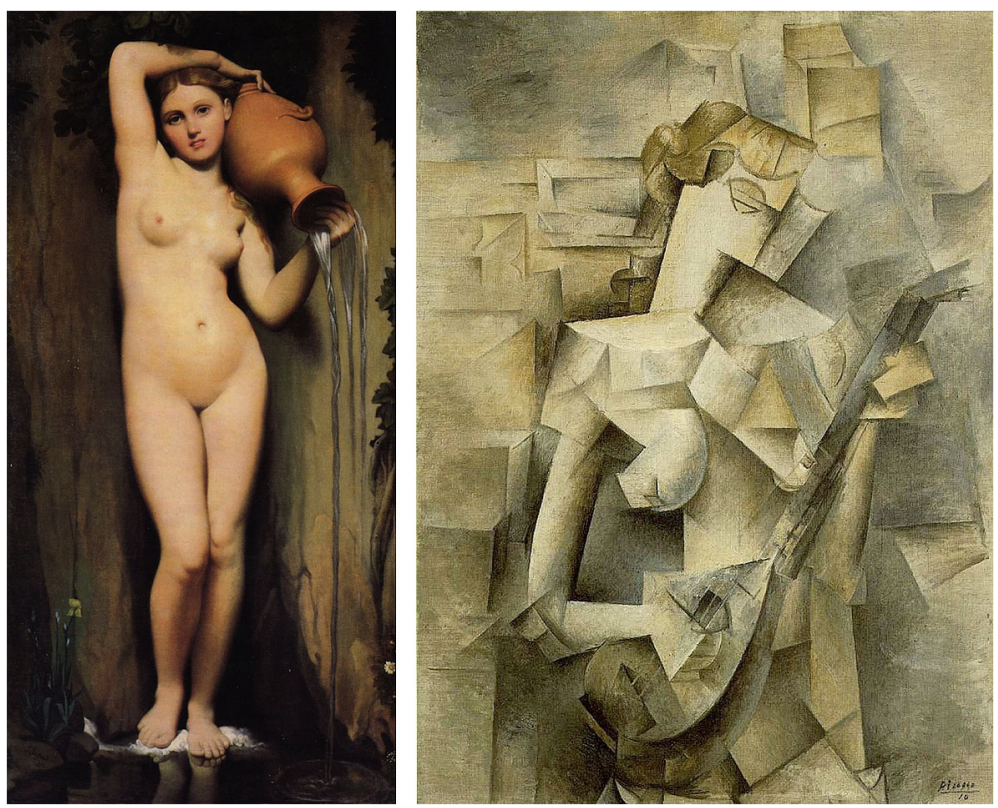

Figure S24. Left: Jean Auguste Dominique Ingres, La source, 1820. The figure appears as a solid body, evidently in front of the background, the background running on behind it. Right: Pablo Picasso, Girl with a Mandolin (Fanny Tellier), Paris, spring 1910. The figure merges into the background, which does not really run on behind the figure. Fluctuating figure-ground distinctions yield a dynamic impression. 


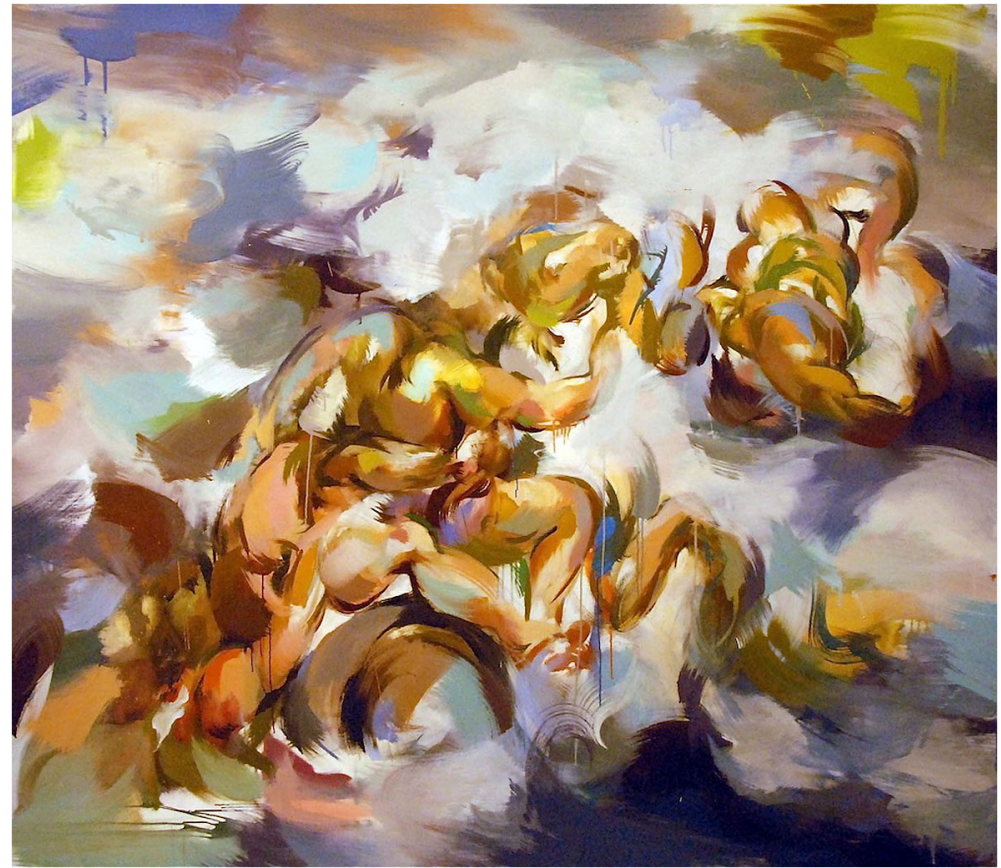

Figure S25. Suzanne Unrein, Rapid East, 2010. The figure-ground distinctions are vague and ambiguous. Thus the painting remains interesting on prolonged looking. 


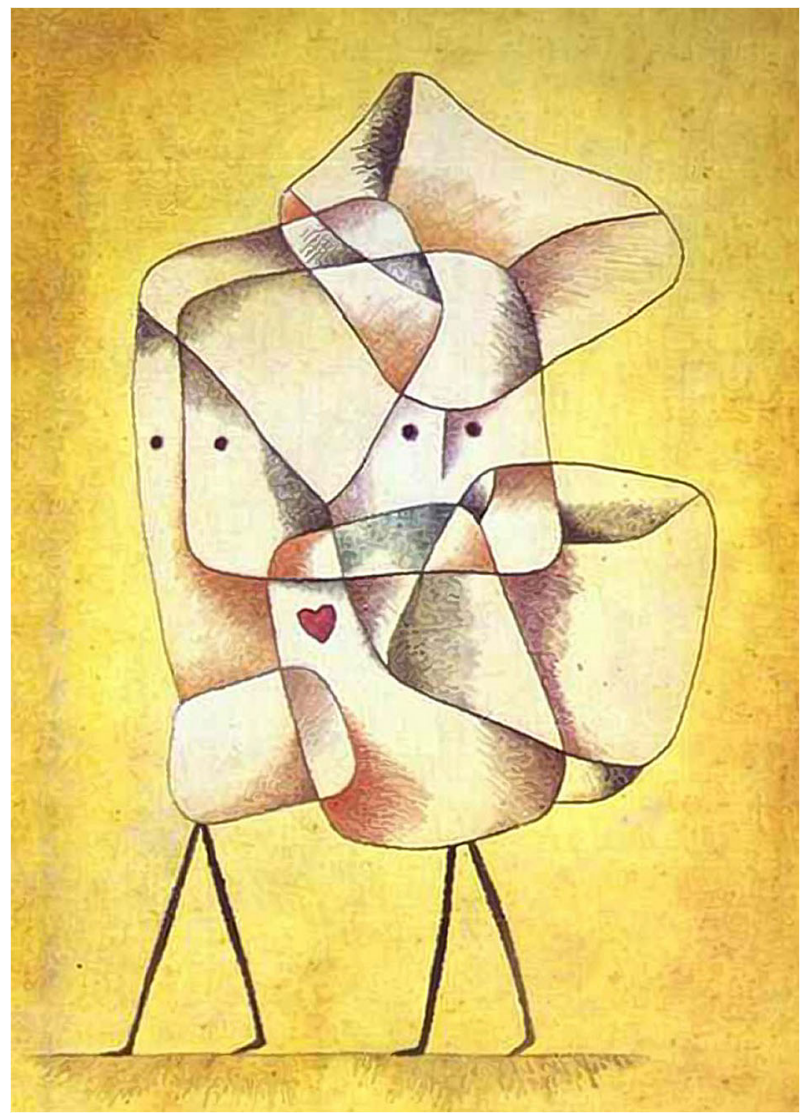

Figure S26. Paul Klee, Brother and sister, 1930. The siblings hold a single heart in common. The drawing has a very tight structure, only a supersurgeon might separate these Siamese twins successfully. 